\title{
INCIDENCE OF GENITAL INFECTION IN MALE PATIENTS WITH ANKYLOSING SPONDYLITIS*
}

\author{
BY \\ J. K. OATES \\ The Whitechapel Clinic, The London Hospital
}

\begin{abstract}
Ankylosing spondylitis is perhaps unique amongst the rheumatic diseases for the consistency with which it has been associated with genital infection. This began some 28 years after its description by Marie (1898), when! he amended a reprint of his original paper with these words "The statement that gonorrhoea plays no part in the origin of spondylitis is incorrect. The study of many cases has led us to believe that gonorrhoea early in the disease plays a very considerable role in its development". Since this time controversy has existed over the part played by gonorrhoea. Many series have been recorded of patients suffering from ankylosing spondylitis with a high incidence of past gonorrhoea, ranging from 10 to 45 per cent. (Dunham and Kautz 1941; Payr, 1946; Thiers, 1949). Equally, other authors have denied the connexion with gonorrhoea and produced series of patients with a very low incidence (from 0 to 5 per cent.) of past gonococcal infection (Lennon and Chalmers, 1948; Young, 1951; McWhirter, 1945). However, few of the figures quoted can be regarded as indicating the true incidence of gonococcal infection, as it is clear that the series nearly always deal with specially selected groups. Furthermore, the earlier figures dealt with a period when gonococcal infections were certainly commoner than they are to-day.
\end{abstract}

It will be seen that attention was concentrated chiefly on the part played by the gonococcus and the possible significance of so-called "non-specific" genital infection was neglected until comparatively recently. Volhard (1948) stated that the prostate was the main focus of infection in spondylitis, but it is clear that he considered gonorrhoea the commonest cause of infection of the gland. Similar views have been expressed by Forestier (1935), and numerous other Continental authors. Dunham and Kautz (1941), from a study of twenty cases of ankylosing

\footnotetext{
* Received for publication July 28, 1958.
}

spondylitis, stated that they did not regard gonorrhoea as bearing a specific relation to the disease, but that a low grade urinary tract infection was present in fourteen of their patients and that such infection, gonococcal and otherwise, was frequently present in the disease. Buckley (1948), who had a vast experience of spondylitis, considered that the prostate played a part in the development of spondylitis, but he thought this was probably due to the diffusion or spread via Batson's venous plexus of alkaline phosphatase elaborated in the gland rather than to an infective or toxic process. Lennon and Chalmers (1948) examined prostatic smears from 32 men with spondylitis with negative results. The part played by genital infection in ankylosing spondylitis was discussed at great length by Romanus (1953), who examined 102 men with spondylitis and found 98 per cent. of them to be suffering from chronic prostato-vesiculitis. He suggested that a spread of infection from the prostate and vesicules via the lymphatics and in particular via the venous plexus described by Batson (1940, 1942) could be held to account for the changes found in the sacro-iliac joints and vertebral column in ankylosing spondylitis. He also adduced some fairly convincing evidence of a definite relationship between this prostatovesiculitis and the onset of spondylitis in approximately 50 per cent. of his cases. He considered that the cause of the prostato-vesiculitis was non-specific and that this genital infection was the commonest cause of ankylosing spondylitis.

Mason, Murray, Oates, and Young (1958) reported a series of 59 patients with ankylosing spondylitis, of whom they found 83 per cent. to be suffering from chronic prostato-vesiculitis. As only 33 per cent. of 83 patients with rheumatoid arthritis were found to have prostatitis judged on the same criteria, it seems probable that their finding is significant. 


\section{Present Investigations}

Selection of Material.-The cases were drawn from three sources: the departments of orthopaedics, physical medicine, and radiotherapy of The London Hospital. The diagnosis in all cases was based upon a complaint of back pain, the finding of rigidity of some part of the spine, frequently a decreased chest expansion, and the presence of radiographic evidence of bilateral sacro-iliitis. 25 patients from the second department, who were previously reported by Mason and others (1958), are included again in the present series. Patients developing ankylosing spondylitis after Reiter's disease, or those who were diagnosed as having ankylosing spondylitis whilst attending the V.D. Clinic have been excluded.

Methods.-The prostate was massaged and after discarding the first drop of secretion appearing at the meatus, five separate specimens of fluid were obtained and immediately examined microscopically for the presence of clumps of pus cells and the average number of pus cells per $1 / 12$ th field. Chronic prostatovesiculitis was diagnosed when clumping of leucocytes was present or when there were ten or more pus cells per 1/12th field. In this series clumping of the leucocytes was present in all cases considered to have prostatitis.

All patients were questioned as to a past history of urethritis, gonococcal or otherwise. They were also asked whether they had noted any disorder of micturition since the onset of their spondylitis.

Results. -82 patients were examined for the presence of prostato-vesiculitis. No specimen of prostatic fluid could be obtained from ten, leaving 72 to be assessed. Of these 72 patients, sixty ( 84 per cent.) were found to have chronic prostato-vesiculitis, whilst in the remainder the prostatic fluid was considered to be normal.

Nine patients were found to be suffering from nonspecific urethritis (N.S.U.) when they were referred for genital examination. Only two of these patients had noted urethral discharge and neither had considered seeking medical advice about the matter. In all cases the discharge was mucopurulent and scanty in amount. Nine of the 82 patients gave a clear history of a past attack of gonococcal urethritis and appropriate treatment. In six the attack of gonorrhoea preceded the development of the first symptoms of spondylitis. The time interval ranged from 13 to 24 months. Eight other patients gave a history of urethral discharge of undetermined origin. In each case this discharge had been noted for a period of a few weeks and several patients had sought the advice of their doctor about it, but none had been given any treatment other than the bottle of medicine. It seems likely that some at least of these were examples of N.S.U. One of them was in the group from which no sample of prostatic fluid could be obtained. Three patients gave a clear history of N.S.U. diagnosed and treated as such. The patients with a clear past history of urethritis and those found to be suffering from N.S.U. totalled 21. (Where a patient fell into one or more of these categories he was counted only once.) These results are summarized in the Table.

TABLE

SUMMARY OF RESULTS IN 82 PATIENTS

\begin{tabular}{|c|c|c|c|c|c|}
\hline \multirow{2}{*}{ Patients Examined .. } & \multirow{2}{*}{$\cdots$} & \multirow{2}{*}{$\cdots$} & \multirow{2}{*}{$\cdots$} & No. & Per cent. \\
\hline & & & & 82 & 100 \\
\hline \multicolumn{3}{|c|}{ Specimens of prostatic fluid obtained } & $\cdots$ & 72 & $87 \cdot 8$ \\
\hline Evidence of prostatitis & $\cdots$ & $\cdots$ & $\cdots$ & 60 & $* 83 \cdot 3$ \\
\hline History of gonorrhoea & $\cdots$ & $\cdots$ & $\cdots$ & 9 & $10 \cdot 9$ \\
\hline History of N.S.U. . . & . & $\cdots$ & $\cdots$ & 3 & $3 \cdot 6$ \\
\hline \multicolumn{4}{|c|}{$\begin{array}{l}\text { History of urethral discharge of undeter- } \\
\text { mined origin } \ldots \\
\text {. }\end{array}$} & 8 & $9 \cdot 7$ \\
\hline Definite urethritis $\ldots$ & $\cdots$ & $\cdots$ & $\cdots$ & 21 & $25 \cdot 5$ \\
\hline Probable urethritis .. & . & $\cdots$ & . & 29 & $35 \cdot 3$ \\
\hline
\end{tabular}

Disturbances of Micturition.-Only six patients admitted to any abnormalities of micturition. In five cases the abnormality was nocturia, and in three of these this symptom began within a year of the onset of spondylitis. Three had to get up twice at night and two once only. These symptoms had persisted for periods varying from 6 months to 3 years. All the patients were below 40 years of age and none had clinically appreciable prostatic hypertrophy. One patient complained of frequency persisting for 18 months after the onset of his rheumatic disease.

\section{Discussion}

The association of chronic prostato-vesiculitis with ankylosing spondylitis found by Romanus (1953) and by Mason and others (1958) is confirmed by this study. That such an association is significant can hardly be denied. The comparable incidence of chronic prostatic inflammation diagnosed on the same criteria as those used here in a normal healthy male population is at the highest about 25-30 per cent. (Oates, 1957). 11 per cent. of patients gave a past history of gonorrhoea. There can be no doubt that patients are very liable to give false answers to questions relating to their sexual habits 
and this frequently extends to information about past attacks of venereal disease. If questions are directly and simply asked, however, many will give correct answers. All the patients questioned were aware that they were being examined with a view to determining the presence of genital disease and this may have helped to ensure the truth of their answers. 11.5 per cent. is perhaps higher than might be expected in a group of "normal" men. Furthermore, in some cases the rheumatic condition appeared to have begun after the attack of gonorrhoea.

Romanus (1953) considered the problem of the relation of gonorrhoea to spondylitis in great detail. He concluded that gonorrhoea was important in the aetiology of spondylitis only in so far as it was a common cause of prostato-vesiculitis, and since it was usually an acute infection would tend to draw attention to its existence earlier and more obviously than the "non-specific" genital infections which are frequently almost asymptomatic. The findings in the present series tend to support Romanus' view, but it does seem that there is often a past history of gonorrhoea in male patients with spondylitis.

If genital infection is a cause of ankylosing spondylitis it becomes a fundamental issue whether the infection is specific or not. Mason and others implied that it might have a specific cause, and that the agent was probably identical with the organism causing most cases of non-gonococcal urethritis; they also stressed that genetic factors were of great importance. Romanus, on the other hand, concluded that the prostato-vesiculitis was a non-specific condition resulting from a variety of different infections, but he also emphasized the importance of hereditary factors. A final answer cannot be reached until more is known of the aetiology of N.S.U. and of the bacteriology of other "non-specific" genital infections.

It is of interest to speculate what effect efficient treatment of these genital disorders may have on the subsequent development and progress of the rheumatic condition. In an illness such as rheumatic fever, where the haemolytic streptococcus is known to be causally related in some way to the disease, Rammelkamp, Wannamaker, and Denny (1952) have shown that penicillin treatment of patients with haemolytic streptococcal throat infections reduces the subsequent incidence of rheumatic fever. Romanus mentions that, in the few cases in which he was able to treat the prostato-vesiculitis "really rationally", there were "strikingly favourable" results in the rheumatic condition. In the presen 1 series no systematic attempt at treatment has been made, and the few patients who claimed improvement in their spondylitic symptoms following therapy (usually with tetracycline by mouth and prostatic massage), may have experienced natural remissions in the course of the disease. This question could only be answered with certainty by long-term observations of two groups of patients with both genital disease and spondylitis of the same duration -one group receiving treatment for the genital infection only. As a clinical trial this would be extremely difficult to undertake. Meanwhile, in the light of our present knowledge, there is a case for thorough treatment and careful follow-up of all male patients with genital infection, in the hope that, in addition to the more obvious benefits of treatment, a few may perhaps be prevented from developing spondylitis or other rheumatic disorders.

\section{Summary}

(1) The evidence of association between genital infection and spondylitis is reviewed.

(2) 84 per cent. of 72 male patients with ankylosing spondylitis were found to have chronic prostatovesiculitis.

(3) Nine of these patients were found to be suffering from N.S.U.

(4) Of 82 male patients with spondylitis, nine gave a history of gonorrhoea and three of nonspecific urethritis. Eight further patients had had urethral discharge of undetermined origin.

(5) The significance of these findings is discussed.

This work was carried out under the aegis of the Medical Research Council Working Party on NonSpecific Urethritis, with the aid of a grant from the U.S. Public Health Service.

I should like to thank Sir Reginald Watson-Jones, Mr. H. Osmond-Clarke, Mr. W. A. Law, Mr. O. J. VaughanJackson, Dr. W. S. Tegner, Dr. R. M. Mason, and Dr. W. Shanks for permission to examine their patients, and Mr. A. J. King for his help and advice.

\section{REFERENCES}

Batson, O. V. (1940). Ann. Surg., 112, 138.

(1942). Ann. intern. Med., 16, 38.

Buckley, C. W. (1948). Ann. rheum. dis., 7, 18

Dunham, C. L., and Kautz, F. G. (1941). Amer. J. med. Sci., 201, 232

Funham, C. L., and Kautz, F. G. (1941).

Lennon, W., and Chalmers, I. S. (1948). Lancet, 1, 12.

Marie, P. (1898). Rev Méd., 18, 285.

Mason, R. M., Murray, R.'S., Oates, J. K., and Young. A. C. (1958). Brit. med. J., 1, 748.

McWhirter, R. (1945). Brit. J'. Radiol., 18, 302.

Oates, J. K. (1957). "XI int. Congr. Derm. Stockholm, 1957". Abs. in Excerpta med. (Amst.), Sect. XIII, 11, 126.

Payr, E. (1946). Chirurg., 17, 26.

Rammelkamp, C. H., Wannamaker, L. W., and Denny, F. W. (1952). Bull. N. Y. Acad. med., 28, 321 .

Romanus, R. (1953a). Acta med. scand., Suppl. 280, p. 196.

Romanus, R. (1953a). Acta med
(1953b). Ibid., pp. 233-241.

(1953c). Ibid., pp. 162-172.

Thiers, H. (1949), Rev. rhum., 16, 636.

Volhard, E. (1948). Dische med. Wschr., 73, 111.

Young, J. H. (1951). Med. J. Aust., 38 (2), 761. 